\title{
Simulated Analysis Of Heavy Duty Car Cab Vibration \\ Feng Xia
}

College of Automobile Technology, Wuxi Vocational Institute of Commerce, Wuxi, Jiangsu, China, 214153

email: jdfengxia@126.com

Keywords: heavy duty car, suspension system, vibration simulation

\begin{abstract}
Comfort is an important performance index of modern cars, and thus car production enterprises are making every effort to improve the comfort level of cabs. The cab suspension system plays a key role in obstructing the vibration passed from the chassis to the cab. A simulated analysis on the car cab suspension system was carried out by using MATLAB/Simulink to improve the comfort of cab vibration.
\end{abstract}

\section{Introduction}

The MATLAB software was applied to analyze the partial frequency changes in the suspension system under different running conditions. A plane model of a heavy-duty car's cab suspension system and Lagrange mathematical model were built, and the frequency response change of the correlation coefficient was calculated. Through the comparison of test results and simulation results, the rationality of the simulation results was verified, and the riding comfort of the cab was improved and a good practical effect was achieved.

\section{Model Design}

A cab model was established by use of ISO coordinate system, and a heavy duty truck cab model was set up by using the Lagrange equation. The cab is provided with full floating supports, and there is a hinged bar on the point $\mathrm{P}$ at the bottom of the cab; in this model, because the damping of the spring below the cab is small, it can be ignored [1]. Thus, a heavy duty truck cab model was built up as shown in Figure 1.

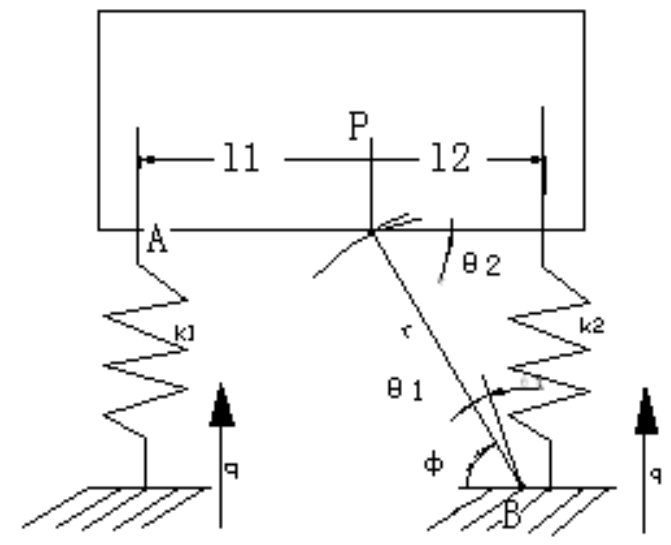

Figure 1 Heavy-duty truck cab model

$m$ - Cab mass, $k_{1}$ and $k_{2}$ - spring stiffness, $j$ - rotary inertia of the point $\mathrm{P}, r$ - length of hinged lever, $l_{1}$ - the distance from the front end of the frame longitudinal beam to the point $\mathrm{P}, l_{2}$ the distance from the back end of the cab to the point $\mathrm{P}, \theta_{1}$ - the turning angle of the hinged bar, $\theta_{2}$ - the swing angle on the point $\mathrm{P}, \phi$ - the angle of the hinged bar and the ground.

According to the formula $\{A\}=[H]\left\{F_{m}\right\}$, the vertical vibration acceleration spectrum at the rear 
lower end of the cab and beneath the copilot seat can be calculated. At this point, $\{F\}$ serves as the exciting force input, and the vertical vibration acceleration response to the front end of the frame longitudinal beam is Fourier transformed and put into the formula above for calculation. $[H]$ is related to the system parameters. Thus this formula:

$$
\left[\begin{array}{cc}
m r^{2} & 0 \\
0 & j
\end{array}\right]\left\{\begin{array}{l}
\ddot{\theta}_{1} \\
\ddot{\theta}_{2}
\end{array}\right\}+\left[\begin{array}{cc}
k_{1} r^{2} \cos ^{2} \phi+k_{2} r^{2} \cos ^{2} \phi & k_{1} r l_{1} \cos \phi-k_{2} r l_{2} \cos \phi \\
k_{1} r l_{1} \cos \phi-k_{2} r l_{2} \cos \phi & k_{1} l_{1}^{2}+k_{2} l_{2}^{2}
\end{array}\right]\left\{\begin{array}{l}
\theta_{1} \\
\theta_{2}
\end{array}\right\}=\left\{\begin{array}{l}
F_{1} \\
F_{2}
\end{array}\right\}
$$

The vertical vibration acceleration response to the rear lower end of the cab and beneath the copilot seat was calculated.

Because the cab suspension system is a secondary suspension system mounted on the frame, the frame was selected as the input point for analysis of the vibration of the cab system[2], and the front-end signals of the frame longitudinal beam available from the test were counted as the input signals of the cab vibration system to calculate the vibration to the rear lower end of the cab and beneath the copilot seat. It was known from the vibration analysis theory that the amplitude of vertical vibration acceleration was related to the structure parameters of the cab vibration system and the frame's input excitation[3].

\section{Test results}

The following four positions are collected in the: (1) the front end of the frame longitudinal beam, (2) the rear lower end of the cab, (3) beneath the copilot seat, (4) the longitudinal beam near the saddle; the acceleration root mean square value of the positions were measured. The measurement method is shown in Figure 2.

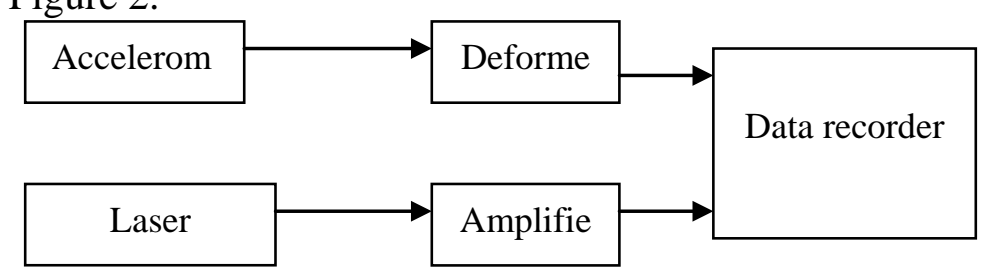

Figure 2 The process of measurement method

The vibration of vehicle system is mainly caused by pavement roughness, and the vibration of vehicle cab is mainly caused by the influence of pavement roughness on the frame system, so when the response to each position of the vehicle is calculated, the front-end vibration response of the frame longitudinal beam can be regarded as an input of the cab vibration system. Vehicle vibration system is a multi-input and single output system[3][4]. According to the vibration analysis theory, the front-end vibration acceleration signal spectrum of the frame longitudinal beam can be used as the input of the cab vibration system, and the input spectrums of the cab vibration system are shown in Figure $3 \sim 5$. The acceleration root mean square value of each position measured respectively from multi-channel signals by means of five times of test acquisition is shown in Table 1. 


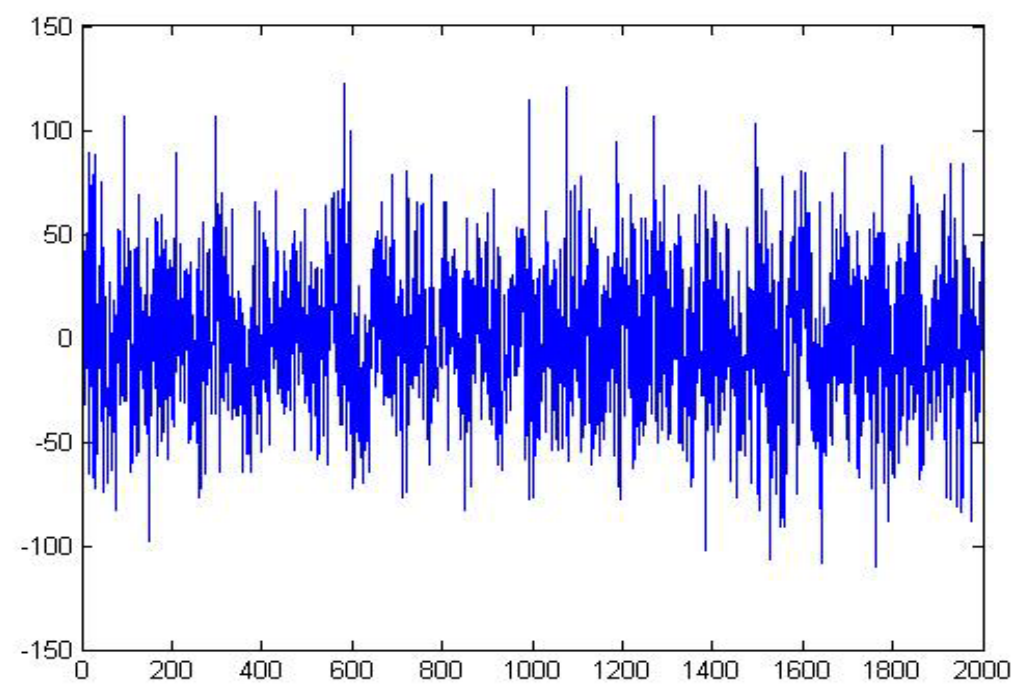

Figure 3 Front-end vibration acceleration signal of the frame longitudinal beam on the asphalt pavement

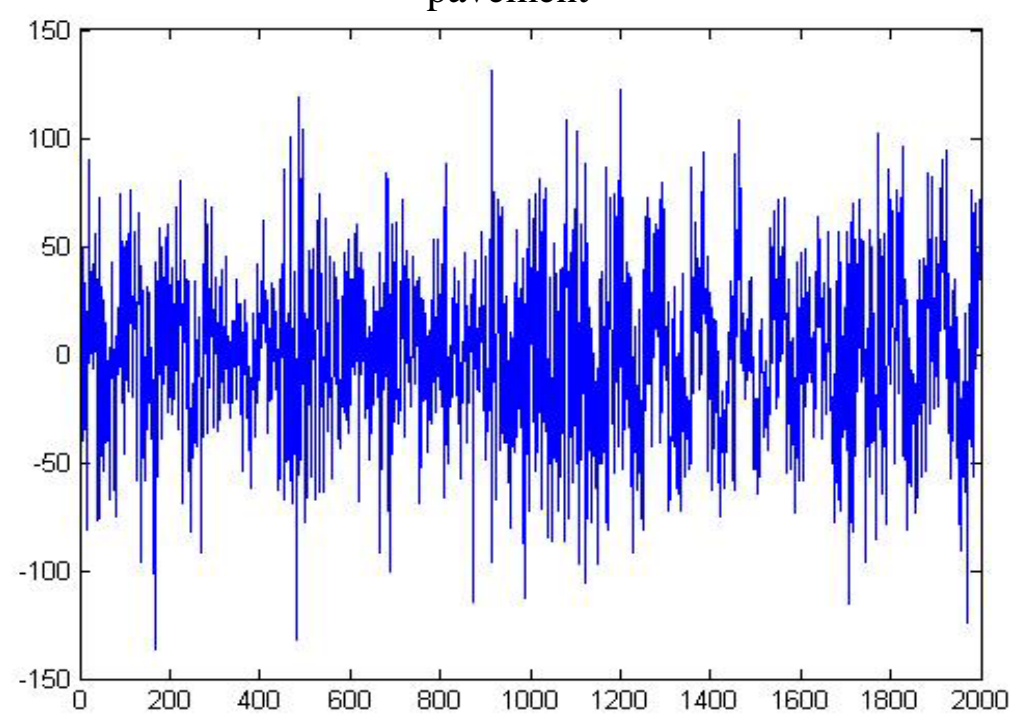

Figure 4 Front-end vibration acceleration signal of the frame longitudinal beam on the stone pavement

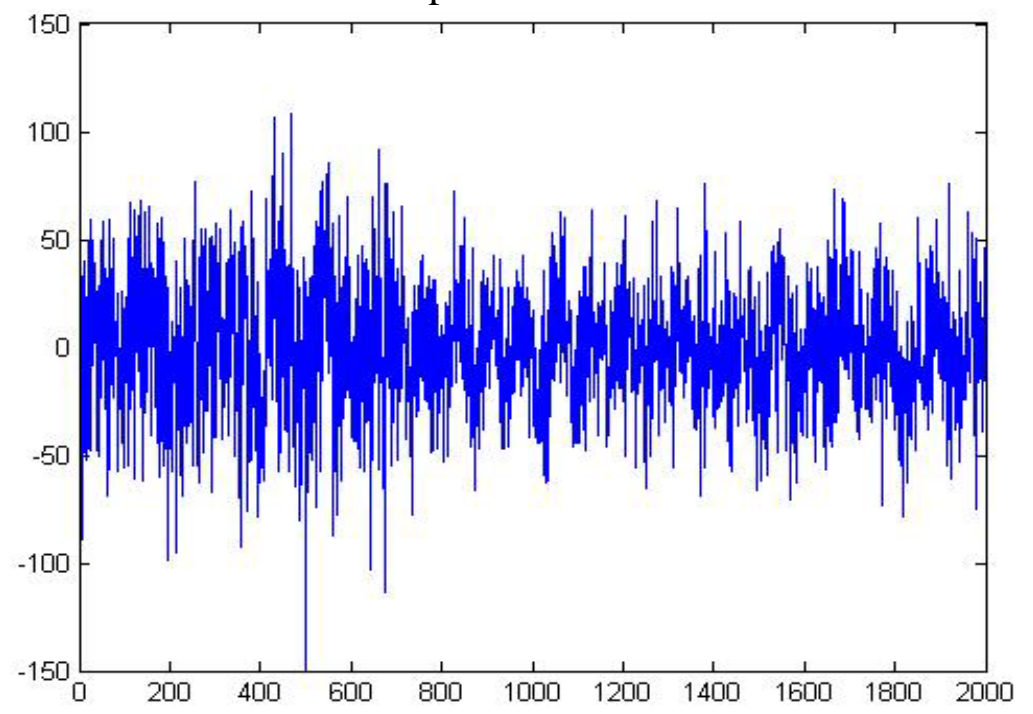

Figure 5 Front-end vibration acceleration signal of the frame longitudinal beam under the idling condition 
Table 1 Root mean square value of acceleration from the test Unit: $\mathrm{m} / \mathrm{s}^{2}$

\begin{tabular}{|c|c|c|c|}
\hline Measuring point & Idle speed & Stone road & Asphalt road \\
\hline $\begin{array}{c}\text { Front end of frame } \\
\text { longitudinal beam }\end{array}$ & 9.167066 & 37.02518 & 33.73041 \\
\hline Rear lower end of the cab & 12.28545 & 35.55425 & 30.90552 \\
\hline $\begin{array}{c}\text { Longitudinal beam near the } \\
\text { saddle }\end{array}$ & 2.356677 & 23.23369 & 12.71447 \\
\hline Beneath the copilot seat & 4.57465 & 25.41798 & 14.31227 \\
\hline
\end{tabular}

\section{Comparison Of The Test Results And Simulation Results}

During the simulation calculation by use of the MATLAB software, the spectrum at the rear lower end of the cab and beneath the copilot seat was separately calculated, and the vibration peak was generated from the system resonance caused by external low-frequency excitation. The vibration peak was caused by the resonance when the vibration frequency and the natural vibration frequency at the rear lower end of the cab and beneath the copilot seat were the same time[5]. After the low frequency vibration of the frame was passed to the cab, the vehicle's riding comfort was affected. The comparison of the test results of cab suspension system measured and the calculated results is shown in table 2.

Table 2 Comparison of resonance frequency test results with simulation results Unit: $\mathrm{Hz}$

\begin{tabular}{|c|c|c|c|c|c|}
\hline \multirow{2}{*}{ No. } & \multirow{2}{*}{ Test } & \multicolumn{2}{|c|}{ Rear lower end of the cab } & \multicolumn{2}{c|}{ Beneath the copilot seat } \\
\cline { 3 - 6 } & Test results & $\begin{array}{c}\text { Calculation } \\
\text { results }\end{array}$ & Test results & $\begin{array}{c}\text { Calculation } \\
\text { results }\end{array}$ \\
\hline 1 & Asphalt pavement & 2 & 2 & 2 & 2 \\
\hline 3 & Pebble pavement & 2 & 2 & 2 & 2 \\
\hline 4 & Stone pavement & 2 & 3 & 3 & 2 \\
\hline 5 & $\begin{array}{c}\text { Fish-scale pits } \\
\text { pavement }\end{array}$ & 2 & 2 & 2 & 3 \\
\hline
\end{tabular}

\section{Conclusions}

The comparison of road test analysis results with spectrum analysis and calculation results shows that close to the peak center frequency, the visible sensitive frequency of the cab system externally excited is about $2 \sim 3 \mathrm{~Hz}$. The vibration acceleration at the rear lower end of the cab and beneath the copilot seat was calculated by using the MATLAB/Simulink software, because the frame's low frequency vibration would affect the steering stability and vehicle riding comfort[6]. Therefore, the automotive cab suspension system can be analyzed effectively using the MATLAB/Simulink software, to improve the driver's comfort while driving.

\section{References}

[1] Zhou Shuiqing. Simulated analysis of car cab suspension system vibration. Journal of Wuhan University of Technology, 2005-1.

[2] Cloud-l. Automobile high speed vibration simulation and experimental research. Highway and 
Transportation Research and Development, 2000-3.

[3] Feng Xia. Vibration analysis of restricting cab suspension system. Noise and vibration control, 2008-2

[4] G. S. Paddan. Evaluation of whole-body vibration in vehicles. Journal of sound and vibration, 2002.

[5] J. A. Tamboli. Optimum design of a passive suspension system of a vehicle subjected to actual random road excitations. Journal of sound and vibration, 1999.

[6] P.Jonsson. Prediction of vehicle discomfort from transient vibrations. Journal of sound and vibration, 2004-2. 